\title{
Integration of Trypanosoma cruzi kDNA Minicircle Sequence in the Host Genome May Be Associated with Autoimmune Serum Factors in Chagas Disease Patients
}

\author{
Augusto Simões-Barbosa, Ana Maria Barros, Nadjar Nitz, Enrique R \\ Argañaraz, Antonio RL Teixeira ${ }^{+}$
}

Laboratório Multidisciplinar de Pesquisa em Doença de Chagas, Universidade de Brasília, Caixa Postal 04536, 70910-900 Brasília, DF, Brasil

Integration of kDNA sequences within the genome of the host cell shown by PCR amplification with primers to the conserved Trypanosoma cruzi kDNA minicircle sequence was confirmed by Southern hybridization with specific probes. The cells containing the integrated kDNA sequences were then perpetuated as transfected macrophage subclonal lines. The kDNA transfected macrophages expressed membrane antigens that were recognized by antibodies in a panel of sera from ten patients with chronic Chagas disease. These antigens barely expressed in the membrane of uninfected, control macrophage clonal lines were recognized neither by factors in the control, non-chagasic subjects nor in the chagasic sera. This finding suggests the presence of an autoimmune antibody in the chagasic sera that recognizes auto-antigens in the membrane of T. cruzi kDNA transfected macrophage subclonal lines.

Key words: horizontal gene transfer - Trypanosoma cruzi kDNA - Chagas disease - autoimmunity

Chagas disease is a chronic, consumptive ailment of protean manifestations affecting the heart, digestive tract, peripheral and central nervous systems, that may be seen in susceptible hosts infected with Trypanosoma cruzi. The acute human infection usually subsides spontaneously. However, chronic Chagas disease is a major public health problem because it produces high rates of morbidity and mortality.

In the absence of correlation between the presence of the parasite and the chronic myocardial lesions, a hallmark of Chagas disease, several authors have shown that autoimmunity plays a major role in the pathogenesis of the disease (Teixeira 1987, Bestetti \& Rossi 1997). Policlonal activation of lymphocytes in the acute infection (Minoprio et al. 1986), the existing shared epitopes between the parasite and the host heart and neuronal tissues (Rizzo et al. 1989, Van Voorkis et al.1991, Cunha-Neto et al. 1995), and the rejection of myocardial cells from normal recipient mice through immunoreactive isogenic $\mathrm{CD}^{+}$and $\mathrm{CD} 8^{+}$ T cells have suggested autoimmunity plays an im-

\footnotetext{
${ }^{+}$Corresponding author. Fax: +55-61-273.4645. E-mail: limacruz@uol.com.br Received 9 June 1999 Accepted 9 August 1999
}

portant role in the pathogenesis of Chagas disease (Ribeiro-dos-Santos et al. 1992, Higushi et al. 1993). However, the origin of immune mechanisms associated with tissue lesions and clinical manifestations of the disease is unknown.

We have observed that $T$. cruzi infected rabbits treated with anti-trypanosomal benznidazole continue to display progressive myocarditis, that is to say, ablation of the parasitemia did not halt progression of the disease (Teixeira et al. 1990). This understanding has allowed us to hypothesize that the intracellular dividing amastigote form of the parasite may integrate its DNA in the genome of the host cell (Teixeira et al. 1991, 1994). Such an integration of exogenous DNA into the genome of the host cell may, as a consequence, produce modification of gene expression. Here we describe results of experiments aimed at the possibility of disclosing the origin of of autoimmune factors that could be associated with wide-ranging manifestations of Chagas disease.

\section{MATERIALS AND METHODS}

Cloning transfected macrophages P388D1-IL1 - Murine macrophages P388D1-IL1 were infected with the Berenice stock trypomastigote forms of T. cruzi at a 5:1 ratio. The cultures were treated with three weekly doses of benznidazole $(100 \mu \mathrm{g} /$ $\mathrm{ml}$ ). Eradication of the infection was confirmed by the absence of parasites in the culture medium, and after successive passages of aliquots of cultures treated in LIT medium and in weanling mice. The 
infected-treated macrophages were subjected to limited dilution cloning on top of a feeder-layer of murine peritoneal macrophages disseminated into each well of a 96-well plate. Single colony growth was transferred to the well of a 24-well plate and then to $25 \mathrm{~cm}^{2}$ culture flasks without feeder-layer. Each colony growth was subjected to PCR analysis. Clonal lines yielding expected PCR amplification products of kDNA were selected for two further rounds of subcloning. This cloning procedure ensured that each kDNA transfected macrophage subclonal line derived from a single cell. The same procedure was used to obtain uninfected macrophage DNA clonal lines.

Polymerase chain reaction (PCR) - PCRs were performed with $T a q$ DNA polymerase (Pharmacia Biotech) following to the manufacturer's recomendation. Template DNAs consisted of cell lysates (Innis et al. 1990) or genomic DNA from: (i) infected-treated macrophages, (ii) uninfected control macrophage and (iii) T. cruzi (negative and positive controls, respectively). Specific primers were used (SK35/36 and SK34/67) for the conserved region of kDNA (Sturm et al. 1989) and for highly repetitive sequences (PON1/2 and Tcz1/2) of nuclear DNA of T. cruzi (Moser et al. 1989, Requena et al. 1992).

Extraction of DNA and Southern hybridizations - DNA was extracted from uninfected control and from transfected macrophage clonal lines. Southern hybridizations were performed with $20 \mu \mathrm{g}$ of DNA digested with restriction enzymes, following the manufacturer's recommendation, and then submitted to $0.6 \%$ agarose gel electroforesis with TBE 1X buffer. The DNA was transferred to a positive charged nylon membrane by capillarity. A kDNA minicircle probe radiolabeled by a random primer was used in the hybridization assays in Denhardt's solution, as described (Sambrook et al. 1989). The membrane was then washed twice at a maximum estringency of $0.2 \mathrm{XSSC}, 0.1 \%$ SDS, at $65^{\circ} \mathrm{C}$ for $30 \mathrm{~min}$, and subjected to autoradiography.

Immunofluorescence assays - Five kDNAtransfected clonal lines (A-to-E) and three uninfected, control macrophage clonal lines (F,G and $\mathrm{H}$ ) were subjected to immunofluorescence assays to detect cell membrane auto-antigens, through recognition by antibodies in chagasic sera. The cells collected in the exponential growth phase were washed three times in PBS, $\mathrm{pH}$ 7.4. They were tested with a panel of sera from ten patients with chronic Chagas disease, and from ten non-chagasic, control individuals. The panel of chagasic sera showed high anti-T. cruzi antibody titers (1:720 and above) in ELISA, indirect immunofluorescence and hemagglutination assays.
The cells were fixed in $3.7 \%$ paraformaldehyde for $10 \mathrm{~min}$, and permeabilized with $0.5 \%$ TritonX100 in PBS for $15 \mathrm{~min}$ at room temperature. After two washings in PBS, the cells were dispensed onto glass slides, air-dried and stored at $-20^{\circ} \mathrm{C}$ till use. The immunologic assay consisted of incubation of aliquots of normal, control macrophage clonal lines, and of transfected macrophage clonal lines, fixed onto glass slides, with serial dilutions of nonchagasic and chagasic sera, for $45 \mathrm{~min}$ in a chamber with humid atmosphere. The cells that were washed three times in PBS and treated with a 1:160 dilution of fluoresceinated rabbit anti-heavy chain human $\operatorname{IgG}$, were incubated for $30 \mathrm{~min}$ under the same conditions. The slides were mounted with coverslips on top of $\mathrm{pH} 9.0$ buffered glycerin and observed under an Axiophot Carl Zeiss fluorescence microscope with 450-490 excitation and, LP 520 barrier filters.

Two-dimensional electrophoresis of membrane proteins - Cultured cells were collected by centrifugation at 2,000 g for $15 \mathrm{~min}$ at $4^{\circ} \mathrm{C}$ and washed twice with PBS, pH 7.5. The cell pellet ressuspended in $3 \mathrm{ml}$ of buffer A (TrisHcl 0,1 M, pH7.5; sacarose $0,25 \mathrm{M}$, Triton X-100 0.5\%, EDTA 20 $\mu \mathrm{M}$, TLCK $20 \mu \mathrm{M}$, E-64 $20 \mu \mathrm{M}$, RAMC $10 \mu \mathrm{M}$, PMSF $8 \mathrm{mM}$ ) was ground in a power driven tissue homogeneizer (Tri-R Instruments, NY) with teflon pestle and glass tube adapted to 0.11 to $0.15 \mathrm{~mm}$ clearance. Rupture of the cells was achieved after five cycles of stirring at 12,000 rpm for $15 \mathrm{sec}$, followed by a 5 -min rest period, at $4^{\circ} \mathrm{C}$. This cell homogenate was centrifugation at $10,000 \mathrm{~g}$ for 15 $\min$ at $4^{\circ} \mathrm{C}$. The supernatant was then ultracentrifuged at $100,000 \mathrm{~g}$ for $2 \mathrm{hr}$ to obtain the cell membrane proteins. Protein determination showed an average of 1300 -to- $1800 \mu \mathrm{g} / \mathrm{ml}$. The cell pellet was ressuspended in a solution containing urea $9 \mathrm{M}$, triton X-100 2\% (v/v), DTT $130 \mathrm{mM}$, PMSF $8 \mathrm{mM}$, and 2\% (v/v) Pharmalyte, $\mathrm{pH} 3-10$.

Two-dimensional electrophoresis was performed with immobiline, $11 \mathrm{~cm}$ drystrip, linear $\mathrm{pH}$ 3-10, for isoelectric focusing and further separation in ExcelGel SDS gradient (8-to-18\%, v/v) following the manufacturer's recommendations (Pharmacia Biotech). A total of $250 \mu \mathrm{g}$ of membrane protein from control (non-transfected) and from transfected macrophage clonal lines was loaded into the gel. Protein spots were detected by silver staining performed, according to the manufacturer's protocol.

\section{RESULTS}

The transfected macrophage clonal lines (Ato-E) template DNA yielded PCR amplification products of expected size when the kDNA primers were used. These template DNA did not yield 
amplification products of expected size when the primers of $T$. cruzi nuclear DNA were used. These findings confirmed the absence of residual T. cruzi infection in the kDNA transfected macrophage clonal lines. The uninfected, control macrophage clonal lines (F, G and $\mathrm{H}$ ) template DNA did not yield PCR amplification products with either sets of $T$. cruzi $\mathrm{kDNA}$ primers.

Southern blot analyses of DNA from transfected macrophage clonal lines showed various patterns of bands formed by hybridization with the minicircle kDNA probe. The different patterns of bands formed, varying from 0.8 to $7.4 \mathrm{~kb}$, depending on the restriction enzyme used, suggest that the sequences of kDNA minicircles are integrated in the host cell DNA (Fig. 1). None of these bands were formed when control uninfected macrophages DNA was hybridized with kDNA minicircle probe.

The immunofluorescence assays showed transfected macrophage clonal lines membrane antigens to be reactive with antibodies in a panel of ten chagasic sera diluted at 1:200 and below. The pat-

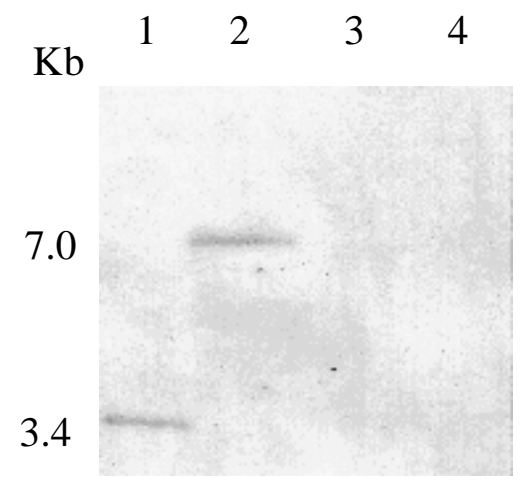

Fig. 1: Southern hybridization of EcoRI and of XhoI digests of DNA from transfected macrophage and from control macrophage clonal lines with a ${ }^{32} \mathrm{P}$-dATP kDNA probe. Lanes 1 and 2, EcoRI and of XhoI digests of transfected macrophage DNA showing 3.4 and $7.0 \mathrm{~kb}$ bands, respectively. Notice absence of bands formed when digests of DNA from control macrophage were used (Lanes 3 and 4).

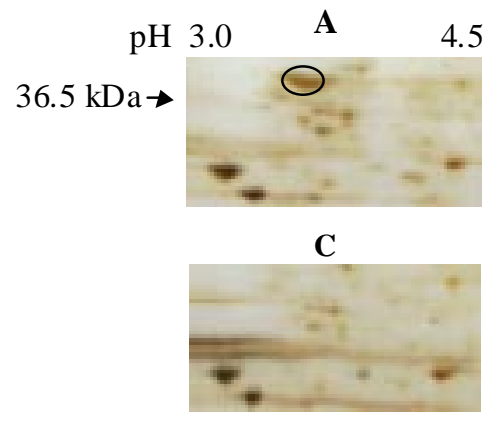

tern of positive fluorescence that was seen in the fixed and permeabilized cell membrane of the transfected macrophage clonal lines A-to-E (Fig. 2) was not seen in the uninfected control macrophage clonal lines F, G and H. Furthermore, differences of membrane protein expression were observed by comparing the pattern of the two-dimensional electrophoresis gel from the uninfected control, and from the transfected macrophage clonal lines, as shown in Fig. 3.

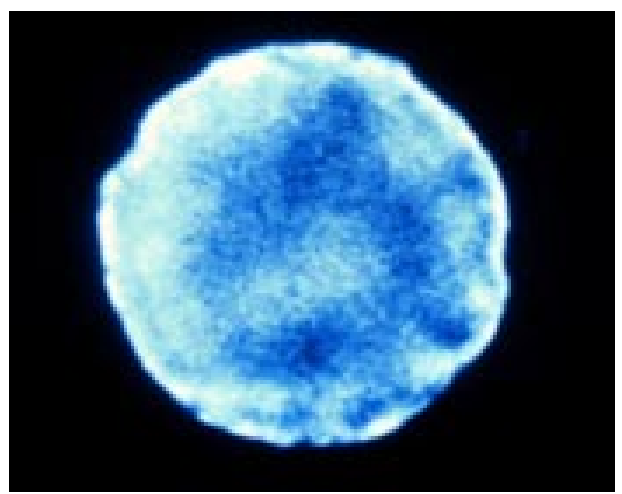

Fig. 2: immunofluorescence staining of membrane proteins of a transfected macrophage clonal line with antibodies in chronic Chagas disease patient serum.

\section{DISCUSSION}

Horizontal transfer of sequences of kDNA minicircle from T. cruzi to the genome of P388D1IL1 macrophages was obtained by natural infection. The cells transfected with the kDNA parasite were cloned and the subclonal lines retained the exogenous DNA after 38 months of twice-weekly serial passages. The kDNA transfected clonal lines remained parasite-free, as demonstrated by PCR amplification products with the $T$. cruzi kDNA primers, and absence of amplification products when the parasite nuclear DNA primers were used. In order to determine the identity of the inserted

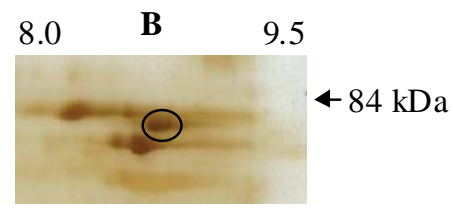

D

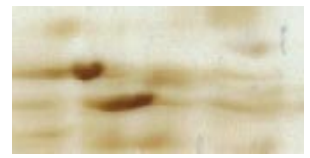

Fig. 3: two-dimensional electrophoresis of membrane proteins. A and B: spots formed when transfected macrophage proteins migrated at $\mathrm{pH} 3.0$-to-4.5 and 8.0-to-9.5. Notice that proteins spots within circles are not present in $\mathrm{C}$ and $\mathrm{D}$, when membrane proteins from control macrophages migrated at same ranges of $\mathrm{pH}$. 
DNA, we performed Southern blot analyses from both uninfected and infected (but parasite-free) macrophage clonal lines. The covalent association of kDNA with host DNA was confirmed in EcoRI and XhoI digests showing a number of bands of different sizes over $1.4 \mathrm{~kb}$, hybridized with kDNA minicircles. None of these bands were found in DNA purified from cell-free preparations of the parasite. The different band sizes may represent insertion fragments between parasite and host cell DNA. These results strongly suggest that sequences of minicircles of kDNA parasite integrated into the host cell by natural infection.

The possibility that $T$. cruzi kDNA integration into the genome of macrophage clonal lines would lead to alteration of the host cell expression was suggested by the immunofluorescence assays. These experiments showed auto-reactive antibodies in the chagasic patients' sera, staining the membrane of the transfected macrophage clonal lines. Furthermore, the membrane of the uninfected, control macrophage clonal lines did not show autoreactive antibody staining. The analysis of twodimensional electrophoresis gel showed protein spots formed with the membrane lysates from transfected macrophage clonal lines, which were not present in the uninfected control macrophage. Attempts to elute differentially expressed proteins in the gel resulting from lysate of the transfected cell line yielded minunte amounts only and, therefore, did not permit sequencing.

These data suggest that the kDNA integration event may alter gene expression of the host cells. We believe that genes differentially expressed in the transfected macrophage, which are not triggered in the uninfected control macrophage clonal lines, will be identified by differential display of mRNA. Further studies will be undertaken to determine whose proteins are up or down regulated. The identification of gene products that are differentially expressed in the kDNA transfected host cells may suggest some of the important autoantigens associated with the origin of autoimmunity that has been described in human and experimental Chagas disease.

\section{REFERENCES}

Bestetti RB, Rossi MA 1997. A rational approach for mortality risk stratification in Chagas heart disease. Intern J Cardiol 58: 199-209.

Cunha-Neto E, Duranti M, Gruber A, Zingales B, De Messias I, Stolf N, Bellotti G, Patarroyo ME, Pilleggi F, Kalil J 1995. Autoimmunity in Chagas disease cardiopathy: Biological relevance of a cardiac myosin specific epitope crossreactive to an immunodominant Trypanosoma cruzi antigen. Proc Natl Acad Sci USA 92: 3541-3545.

Higushi M de L, Gutierrez PS, Aiello VD, Palomino S,
Bocchi E, Kalil J, Belloti G, Pileggi F 1993. Immunohistochemical characterization of infiltrating cell in human chronic chagasic myocarditis: comparision with myocardial rejection process. Virchows Arch A Pathol Anat Histopathol 423: 157-160.

Innis MA, Gelfand DH, Sninsky JJ, White TJ 1990. PCR Protocols, A Guide to Methods and Applications, Chapter 18, p.146-152. Academic Press, New York.

Minoprio P, Eisen H, Fomi L, D'Imperio Lima MR, Joskowicz M, Coutinho A 1986. Polyclonal lymphocyte response to murine $T$. cruzi infection I. Quantitation of both T and B-cell responses. Scand J Immunol 24: 661-668.

Moser DR, Kirchhoff LV, Donelson JE 1989. Detection of Trypanosoma cruzi by DNA amplification using the polymerase chain reaction. J Clin Microbiol 27: 1477-1482.

Requena JM, Jimenez-Ruiz A, Soto RM, Lopez MC, Alonso C 1992. Characterization of a highly repeated interspersed DNA sequence of Trypanosoma cruzi: its potential use in diagnosis and strain classification. Mol Biochem Parasitol 51: 271-280.

Ribeiro-dos-Santos R, Rossi MA, Laus JL, Silva JS, Savino W, Mengel J 1992. Anti CD-4 abrogates rejection and reestablishes long-term tolerance to syngenic newborn hearts grafted in mice chronically infected with Trypanosoma cruzi. J Exp Med 175: 29-39.

Rizzo LV, Cunha-Neto E, Teixeira ARL 1989. Autoimmunity in Chagas disease: specific inhibition of reactivity of CD4+T cells against myosin in mice chronically infected with Trypanosoma cruzi. Infect Immun 57: 2640-2644.

Sambrook J, Fritsh EF, Maniatis T 1989. Molecular Cloning. A Laboratory Manual, Cold Spring Harbor, New York.

Sturm NR, Degrave W, Morel C, Simpson L 1989. Sensitive detection and schizodeme classification of Trypanosoma cruzi cells by amplification of kinetoplast minicircle DNA sequences: use in diagnosis of Chagas disease. Mol Biochem Parasitol 33: 205 214.

Teixeira ARL 1987. Doença de Chagas e Outras Doenças por Tripanossomos, Universidade de Brasília, Brasília, 161 pp.

Teixeira ARL, Argañaraz ER, Freitas Jr LM, Lacava ZGM, Santana JM, Luna H 1994. Possible integration of Trypanosoma cruzi kDNA minicircles into the host cell genome by infections. Mut Res 305: 197-209.

Teixeira ARL, Cordoba JC, Souto-Maior Solorzano E 1990. Chagas disease: lymphoma growth in rabbits treated with benznidozole. Am J Trop Med Hyg 43: 146-158.

Teixeira ARL, Lacava ZL, Santana JM, Luna H 1991. Inserção de DNA de Trypanosoma cruzi no genoma da célula hospedeira de mamíferos por meio de infecção. Rev Soc Bras Med Trop 24: 55-58.

Van Voorkis WC, Schlekewy L, Trong HL 1991. Molecular mimicry by Trypanosoma cruzi: the F1-160 epitope that mimics mammalian nerve can be mapped to a 12-amino acid peptide. Proc Natl Acad Sci USA 88: 5993-5997. 